\title{
Bone formation in $\beta$-tricalcium phosphate-filled bone defects of the rat femur: Morphometric analysis and expression of bone related protein mRNA
}

\author{
Kiyoto Shiratori ${ }^{1}$, Kenichi Matsuzaka ${ }^{2}$, Yoshihiko Koike ${ }^{2}$, Satoshi Murakami ${ }^{2}$, Masaki Shimono ${ }^{1}$ and Takashi \\ INOUE $^{2}$ \\ ${ }^{1}$ Department of Pathology and ${ }^{2}$ Department of Clinical Pathophysiology, Oral Health Science Center, Tokyo Dental College, 1-2-2 Ma- \\ sago, Mihama-ku, Chiba 261-8502, Japan
}

(Received 22 November 2004; and accepted 23 January 2005)

\begin{abstract}
The purpose of the current study was to evaluate the bone formation when $\beta$-tricalcium phosphate (TCP) was implanted in bone defects of rat femurs. $\beta$-TCP granules were applied to defects created in the femurs of 65 male rats who were sacrificed 3, 7, 10, 14 or 30 days later. Bone tissues were embedded in paraffin, serial sections were cut and then stained with hematoxylin-eosin. Histomorphometric analyses were also conducted. Furthermore, total mRNAs were extracted, homogenized, and reverse transcribed, after which quantitative PCR assays were conducted with a LightCycler ${ }^{\mathrm{TM}}$ using the double-stranded DNA dye Syber Green I with primers for either rat osteopontin or osteocalcin. Tissues in defects without $\beta$-TCP were used as controls. The amount of newly formed bone tissue in the $\beta$-TCP implanted group was significantly greater in both the side areas and the central area of defects than in the control group. Expressions of osteopontin and osteocalcin mRNAs of cells in the defects of the experimental group were up-regulated compared with the control group at all time periods. Taken together, these results prove that $\beta$-TCP is an appropriate material for osteoconduction and promotes bone formation in bone defects.
\end{abstract}

It is known that bone tissues exhibit a strong regenerative potential and can perfectly restore the original structures and their mechanical properties. However, these capacities have limits and may even fail if certain conditions are not fulfilled. Some factors that impede bone repair are: failure of vascularity, mechanical instability, oversized defects, and competition with tissue of high proliferative activity such as fibrous connective tissue (30). Failure of vascularity and mechanical instability are commonly associated with fractures, and often result in nonunion of the bone. Interruption of the blood supply

Address correspondence to: Prof. Takashi Inoue Oral Health Science Center, Department of Clinical Pathophysiology, Tokyo Dental College, 1-2-2 Masago, Mihama-ku, Chiba 261-8502, Japan

Tel: +81-43-270-3673, Fax: +81-43-270-3583

E-mail: inoue@tdc.ac.jp causes necrosis of bone fragments or their ends and impairs bone union. Loss of fragments or surgical removal of necrotic fragments creates defects that are often too large to be filled spontaneously with bone. Finally, cells in neighboring soft tissues might proliferate more rapidly and occupy the defective sites faster than the bone can grow. This phenomenon leads to scar formation at the site of wound healing without bone formation. To avoid these problems, the use of barrier membranes to facilitate bone healing was developed $(3,13)$, and then tested in different types of bone defects and dental implants, both experimentally and clinically $(5,7,26)$. Even though membranes are used to treat bone defects, larger defects are usually not filled with sufficient bone tissues.

Filling of larger bone defects is greatly facilitated by osteoconduction, i.e., the provision of a framework or scaffold that serves as a template and an 
enlarged solid base for bone deposition (30). Bone autografting is known to be the gold standard for bone reconstruction $(17,31,33)$. However, autogenic bone grafting always requires a second operation site and may cause various degrees of morbidity in the donor area. Also, when the amount of donor bone is not sufficient, the gain in bone volume might be minor. Moreover, free block autografts may undergo either partial necrosis or resorption, because of prolonged ischemia and insufficient subsequent revascularization $(1,4,27)$. These facts suggest that bone substitutes may be used as an augmentation procedure when the supply of autogenic bone is limited.

The use of bone substitutes in augmentation procedures can: 1) maintain the space available for tissue ingrowth, 2) enhance osteoconduction by forming a porous framework, and 3) prevent wound contraction by stabilizing blood clots and the subsequent provisional matrix (12).

Allografts, as well as some bone-derived or synthetic bone substitutes, have osteoconductive properties (21). However, degradation and substitution by viable bone is often poor. If the implanted material is not able to be resorbed, as in the case of certain porous hydroxyapatite implants, the incorporation is restricted to bone apposed to the material surface, and no substitution occurs during the remodeling phase. Resorbable tricalcium phosphate (TCP) ceramics (such as $\beta$-TCP) of identical initial structure undergo resorption and extensive substitution under the same experimental conditions (10). Some studies have examined the behavior of osteoblasts around implanted $\beta$-TCP granules using in situ hybridization in rats $(9,20,22-25)$ and other studies have investigated mRNA expression in osteoblasts around the $\beta$-TCP $(23,28)$. However, little is known about cell behavior around $\beta$-TCP. The purpose of the current study was to evaluate the activity of rat bone marrow cells when $\beta$-TCP was implanted in bone defects of rat femurs using histomorphometric analysis and evaluation of mRNA expression for bone related protein.

\section{MATERIALS AND METHODS}

All experiments were performed in accordance with the animal facility guidelines of the Tokyo Dental College.

Sixty-five Sprague-Dawley male rats, $200 \mathrm{~g}$ in body weight, were used in this study. Wounds were made according to the method described by Inoue et al. (14). Briefly, a skin incision, approximately $3.0 \mathrm{~cm}$ in length, was made along the lateral aspect of the right thigh, and the femoral muscles were retracted to expose the lateral aspect of the femur. A defect approximately $1 \times 5 \mathrm{~mm}$ in diameter was produced in the mid-region of the lateral aspect of the femoral diaphysis, using a \#3 round bur mounted in a slow-running dental hand piece cooled with phosphate-buffered saline, $\mathrm{pH}$ 7.0. The underlying bone marrow was excised with a dental excavator and debris was removed by washing with phosphate-buffered saline. $\beta$-TCP (Osferion; Olympus Co., Tokyo, Japan), a whitish material and $0.5-1.5 \mathrm{~mm}$ in diameter with $75 \%$ porosity (framework porosity of 100 to $200 \mu \mathrm{m}$, was crushed by mechanical means and implanted in the bone cavity. The muscle was sutured with 3.0 silk suture and the skin with 4.0 silk. Cavities without $\beta$-TCP implants were used as controls.

Histological preparations. Five rats each were sacrificed by an overdose of ether at 3, 7, 10, 14 and 30 days after the implantation. The implants and surrounding tissues were removed and fixed in 37\% formaldehyde: $99.9 \%$ methanol: distilled water $(1: 1: 1.5 \mathrm{v} / \mathrm{v})$ for $48 \mathrm{~h}$, and then decalcified in $10 \%$ EDTA for 7 days at room temperature. All specimens were washed in running water for $12 \mathrm{~h}$ and were then dehydrated with ethanol before being embedded in paraffin. Serial sections, approximately 5 $\mu \mathrm{m}$ thick, were cut parallel to the long axis of the femur in which $\beta$-TCP was included and were stained with hematoxylin and eosin. This investigation aimed to evaluate and quantitate newly formed bone tissue in the defects.

Morphometric analysis. The choose sites for measurement, the section was divided into three equal parts; the central area and the side areas (Fig. 1). The following features were quantitated: (1) the side or central area of the bone defect, (2) the total area of $\beta$-TCP in the side or central area of the bone defect; and (3) the area of bone deposition in the side or central area of the bone defect. Bone formation ratio and $\beta$-TCP ratio were calculated.

Measurements were made on five sections from each of the defects at each of the time periods by means of a Digital Equipment Corporation computer (using NIH image analyzer software). The results for each tissue are expressed as the ratio of the mean of the area of bone in relation to that of the defects (mean $\pm \mathrm{SD}$ ). Analysis of variance and the multiple comparison Fisher's test were used to analyze the data. 


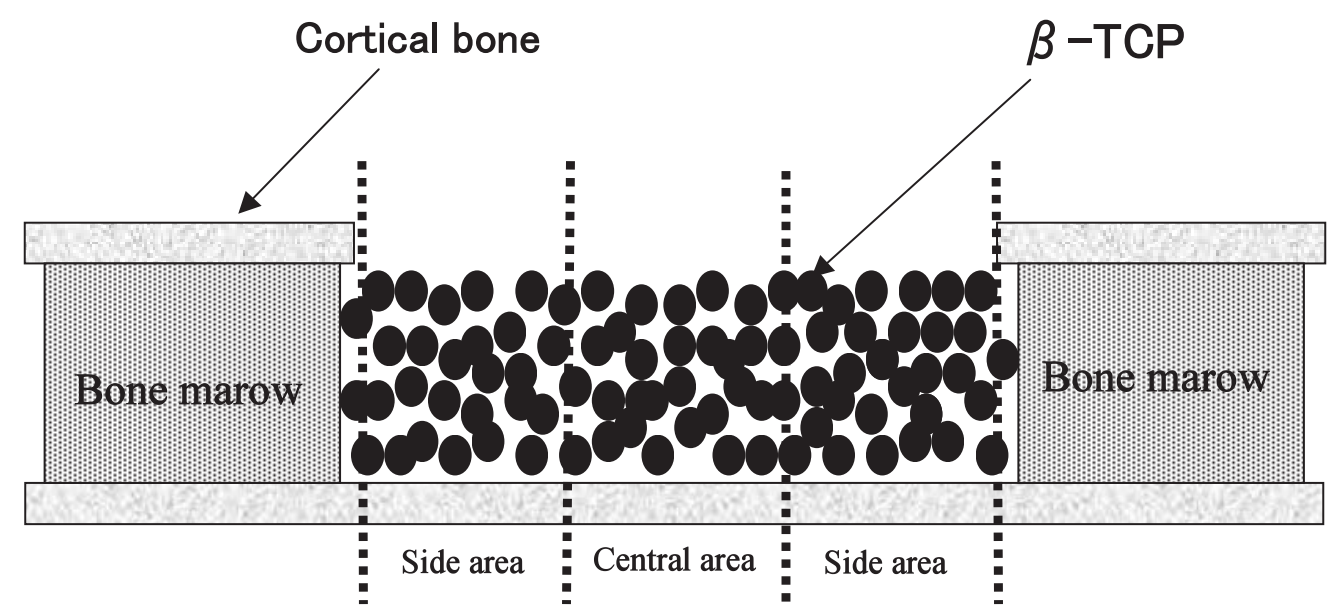

Fig. 1 Scheme showing the method for morphometric analysis. Specimens were divided into three equal parts; the side or central area of the bone defect. The area of $\beta$-TCP and the area of bone deposition in the side or central area of bone defect were measured. Bone formation ratio and $\beta$-TCP ratio were calculated.

Preparation of samples for quantitative RT-PCR using the LightCycler ${ }^{\mathrm{TM}}$. Eight animals each were sacrificed at $3,7,10,14$ and 30 days after the operation. Each femur was cut finely by ophthalmic scissors and bone scissors. Implanted areas were removed and were homogenized using a SONIFIER (BRANSON, Dunbury, CT, USA) in TRIZOL REAGENT (Invitrogen, Carisbad, CA, USA) and total RNA was extracted. Suspensions to which chloroform was added were centrifuged at $13200 \mathrm{rpm}$ for 20 min after shaking. The supernatants were recovered and isopropyl alcohol was added, then shaken and frozen at $-80^{\circ} \mathrm{C}$ overnight. Subsequently, the samples were centrifuged at $13200 \mathrm{rpm}$ for $20 \mathrm{~min}$ and total RNA pellets were produced and washed with $75 \%$ ethanol. Finally, the total RNA pellets were dissolved in RNase free water, and preserved at $-80^{\circ} \mathrm{C}$ until use. The total RNA was measured by absorbance in a UVmini-1240 spectrometer (Shimadzu Corp, Kyoto, Japan). Oligo dT primer: $1 \mu$, dNTP: $2 \mu$, RNase inhibitor: $1 \mu \mathrm{l}$, reverse transcriptase: $1 \mu \mathrm{l}, 10 \times$ buffer: $2 \mu \mathrm{l}$ and $\mathrm{MgCl}_{2}: 4 \mu \mathrm{l}$ were added to total RNA: $1 \mu \mathrm{g}$ and the entire quantity was adjusted to $20 \mu \mathrm{l}$ with RNase free water. The mixed solutions were subjected to reverse transcription reactions $\left(42^{\circ} \mathrm{C}, 15 \mathrm{~min}, 99^{\circ} \mathrm{C}, 5 \mathrm{~min}\right)$ to synthesize cDNA. PCR was then carried out to measure osteopontin and osteocalcin. Primer sequences used for osteopontin were (from 5' to 3'), forward; CTC GGA GGA GAA GGC GCA TTA, and reverse; CCA TCG TCA TCG TCG TCG TCA. Primer sequences used for osteocalcin were (from 5' to 3'), forward; GGT GCA AAG CCC AGC GAC TCT, and reverse; GGA AGC CAA TGT GGT CCG CTA.
The housekeeping gene glyceraldehyde-6-phosphate dehydrogenase (GAPDH) was also measured as a control and its primer sequences from 5' to 3' were, forward; TGA ACG GGA AGC TCA CTG G, and reverse; TCC ACC ACC CTG TTG CTG TA. To quantitate mRNA levels, a quantitative PCR assay was conducted with a LightCycler ${ }^{\mathrm{TM}}$ using the double-stranded DNA dye SYBR Green I (Roche Diagnostics, Mannheim, Germany). Quantification was performed by comparison of the levels obtained to standardized samples. The PCR conditions used in the LightCycler ${ }^{\mathrm{TM}}$ were 45 cycles $\left(95^{\circ} \mathrm{C}, 10 \mathrm{sec}, 60\right.$ ${ }^{\circ} \mathrm{C}, 5 \mathrm{sec}$ and $72^{\circ} \mathrm{C}, 12 \mathrm{sec}$ ). Melting curve analysis was also performed after the PCR amplification to confirm the absence of the primer dimer in the PCR products. The PCR products were then separated on $2 \%$ agarose gels containing ethidium bromide.

\section{RESULTS}

\section{Histological observations}

Control groups

Three days after the surgery, both the central and the side areas of each defect were occupied by hemorrhages with small round cell infiltrations. Seven days after the surgery, blood clots were still observed in the central area; however a copious amount of newly formed woven bone was observed in the side areas (Fig. 2). Ten and 14 days after the surgery, newly formed woven bone was observed in the central area but woven bone in the side area tended to decrease in extension. Thirty days after the surgery, all the woven bone tissue in the defects had been completely absorbed and replaced by bone 

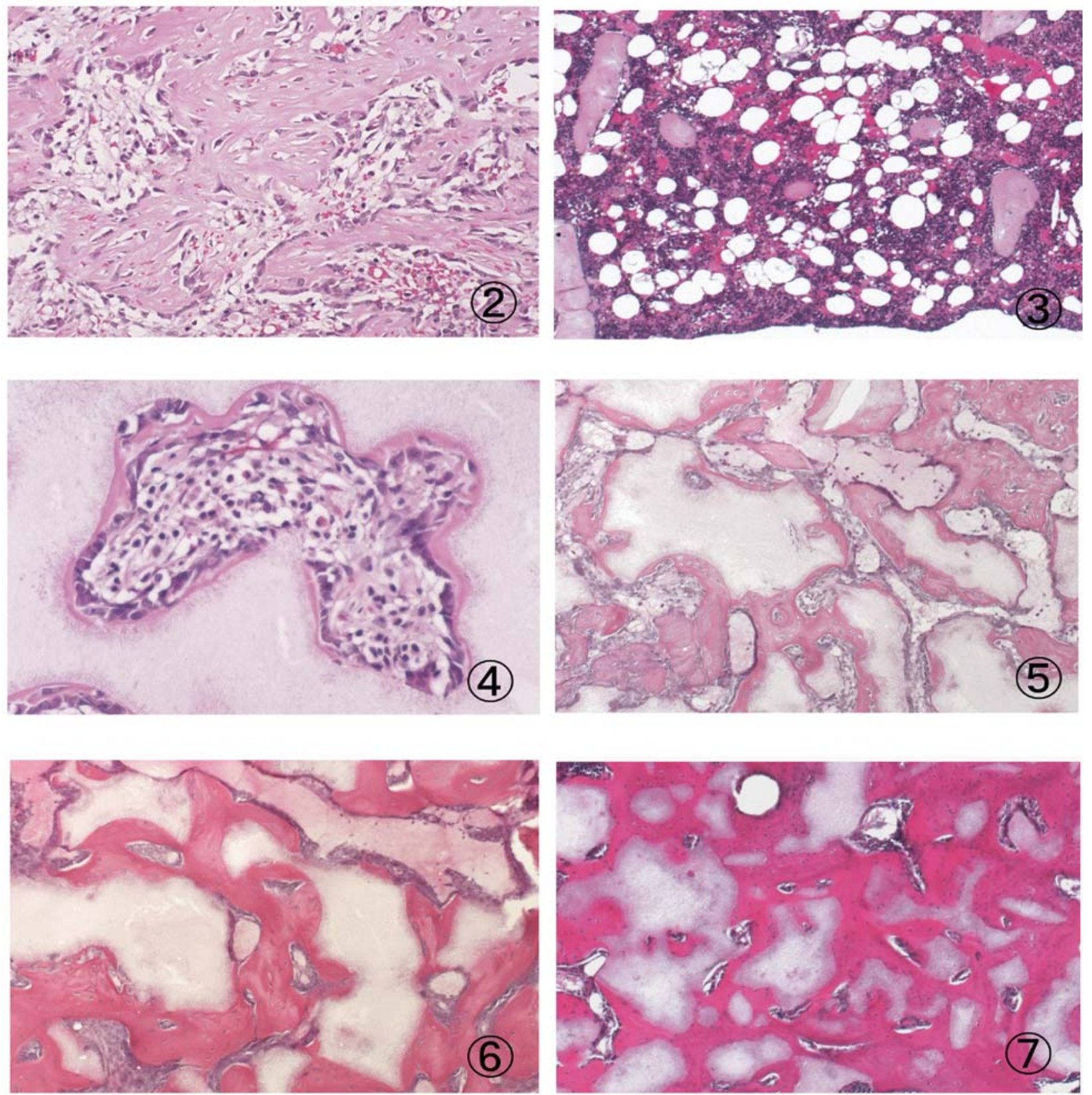

Figs. 2-7 H\&E staining of tissues during the bone repair.

Fig. 2 At 7 days in the control group, copious amounts of newly formed fibrous bone were observed in the side areas of the bone defect. X200

Fig. 3 At 30 days in the control group, newly formed woven bone tissues disappeared and were replaced by bone marrow tissues. X200

Fig. 4 At 7 days in the experimental group, new bone was deposited on the $\beta$-TCP and osteoblast-like cells were aligned on the bone tissue. $\mathrm{X} 1,000$

Fig. 5 At 10 days in the experimental group, newly formed woven bone formation between $\beta$-TCP tended to increase. X200

Fig. 6 At 14 days in the experimental group, resorption of $\beta$-TCP was observed. X200

Fig. 7 At 30 days in the experimental group, $\beta$-TCP was replaced by bone tissue. X200 
marrow cells (Fig. 3).

\section{Experimental groups}

Three days after the implantation, the side area of each defect was filled with blood clots, while some woven bone and fibrin materials were observed around the $\beta$-TCP granules in the central areas. Seven days after the implantation, both the side and the central areas were colonized by woven bone, where new bone tissue had been deposited on the $\beta$-TCP and osteoblast-like cells were aligned on the newly formed bone (Fig. 4). Ten and 14 days after the implantation, woven bone formation around the $\beta$-TCP tended to increase (Fig. 5) and replacement of $\beta$-TCP with bone tissue was observed (Fig. 6). Thirty days after the implantation, $\beta$-TCP still occupied about $30 \%$ of the bone defects , however, no osteoclasts were related to the resorption of $\beta$-TCP (Fig. 7).

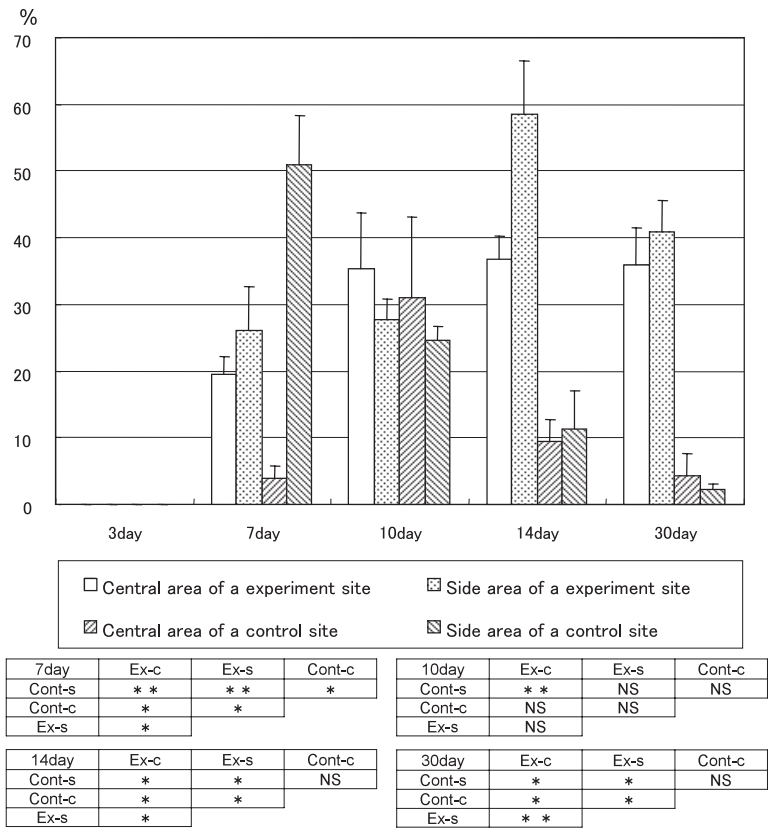

$* * \mathrm{P}<0.05 \quad * \quad \mathrm{P}<0.01$

Fig. 8 Statistical analysis of the morphometric study for the area of bone tissue in the defect. In the control group, bone formation in the side area was significantly increased over that in the central area at 7 days $(P<0.01)$, but decreased its volume day by day until 30 days. There were no significant differences between the central and the side areas at 10, 14 and 30 days in control groups. In the $\beta$-TCP implanted groups, there were no significant differences between the central and the side areas at 10 days. However, newly formed bone tissue was significantly increased in the side area compared with the central area at 14 and at 30 days $(P<0.01)$.
Statistical analysis of the morphometric study (Fig. 8) At 3 days after implantation, newly formed bone could not be observed in either the control or the experimental groups. In the control group, bone formation in the side area was significantly increased over the central area at 7 days $(\mathrm{P}<0.01)$, but its volume decreased day by day until 30 days and there were no significant differences between the central and the side areas at 10, 14 and 30 days. In the $\beta$-TCP implanted groups there were no significant differences between the central and the side areas at 10 days. However, newly formed bone tissue was significantly increased in the side area compared with the central area at $7(\mathrm{P}<0.01), 14$ $(\mathrm{P}<0.01)$ and 30 days $(\mathrm{P}<0.05)$. Newly formed tissue in the $\beta$-TCP implanted groups was significantly higher than the control groups at 14 and 30 days $(\mathrm{P}<0.01)$. The areas of $\beta$-TCP in the bone defects at 3 days were significantly higher than the oth-
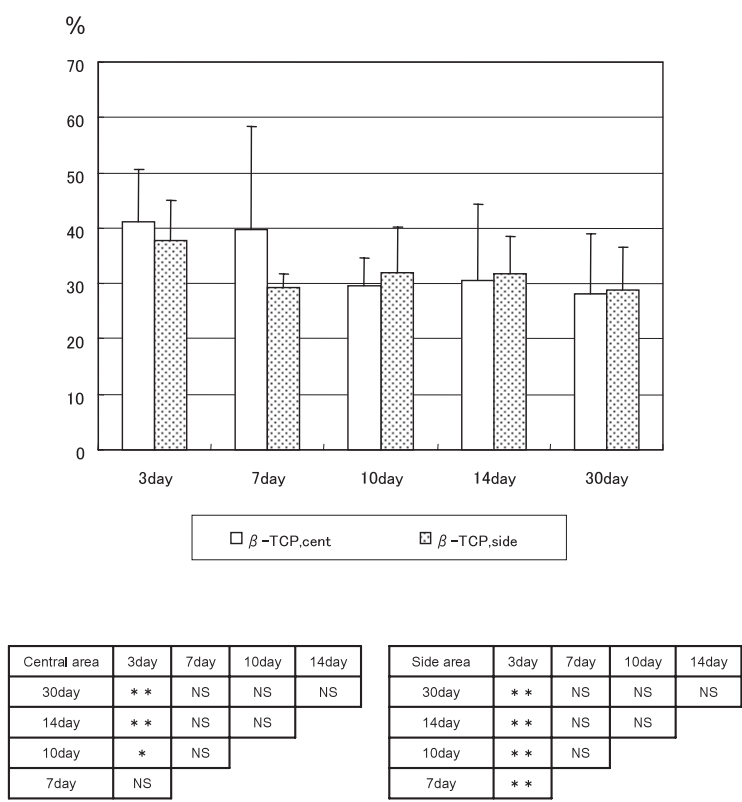

$* * \mathrm{P}<0.05 * \mathrm{P}<0.01$

Fig. 9 Statistical analysis of the morphometric study for the area of $\beta$-TCP. The side area of $\beta$-TCP at 3 days was significantly greater than the other days $(P<0.05)$. The central area of $\beta$-TCP at 3 days was significantly greater than day $10(P<0.01)$ and days 14 and $30(P<0.05)$. 
er time periods both in the central and in the side areas (Fig. 9).

\section{Osteopontin and osteocalcin mRNA expression}

Osteopontin mRNA expression was continuously observed throughout the experimental periods in the control and in the experimental groups (Fig. 10). Osteopontin mRNA expression was greater in the $\beta$-TCP implanted groups than in the control groups at all of the time periods and significant differences were observed at only 10 days $(\mathrm{P}<0.05)$. The expression was greatest at 10 days and suddenly decreased thereafter in both groups.

Osteocalcin mRNA expression was also continuously observed throughout the experimental periods in the control and in the experimental groups (Fig. 11). Osteocalcin mRNA expression was detected earlier and at higher levels in the $\beta$-TCP implanted groups than in the control groups and significant differences were observed at $7(\mathrm{P}<0.01)$ and 14 days $(\mathrm{P}<0.05)$.

\section{DISCUSSION}

\section{Osteoconduction of $\beta$-TCP}

The reconstruction of skeletal deficiencies presents a challenging problem to the dental community with respect to denture treatment and implant dentistry.

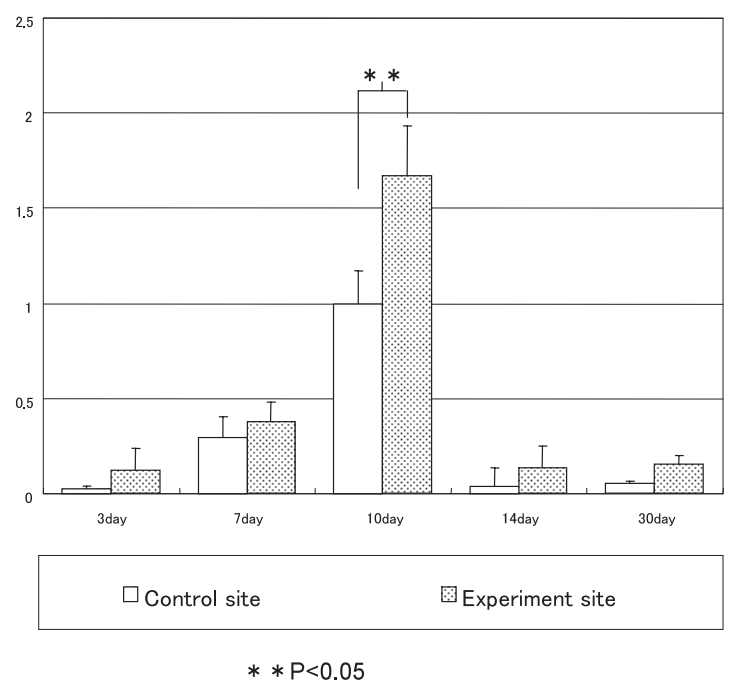

Fig. 10 Osteopontin mRNA expression was continuously observed throughout the experimental periods in the control and in the experimental groups. Osteopontin mRNA expression was also greater in the $\beta$-TCP implanted groups than in the control groups at all of the time periods and significant differences were observed at only 10 days. The expression level peaked at 10 days and then suddenly decreased day by day in both groups.
Such defects can result from trauma, periodontal disease, infection, or tumor resection. Even a minor defect in the jaw bone may cause a significant problem. To resolve such problems, fresh autogenous bone grafts are one of the most common methods to create new bone $(10,19,30)$. Because there is no risk of any autoimmune reaction, a prompt transplantation keeps many cells alive. In the treatment of extensive defects, however, autografts also have restrictions, mainly because of limits on their availability. Microvascular, corticospongious transplants are technically demanding and often do not reconstruct a full-sized substitute. These facts suggest that bone substitutes must be used in augmentation procedures.

Filling of bone defects using bone substitutes is greatly facilitated by osteoconduction, i.e. by offering a framework or scaffold as a template for an enlarged solid base for bone deposition. Certain conditions must be fulfilled for successful osteoconduction, 1) the scaffold must consist of bioinert or bioactive materials, 2) the shape and dimensions of the external and internal structures should favor osteoprogenitor cell ingrowth from the recipient bed into the structure (framework), and 3) bone deposition must occur on the substitutes (30).

Johner (16) examined the healing of bones with holes of diameters between 100 and $1000 \mu \mathrm{m}$ in the tibia of rabbits. That study reported that bone for-

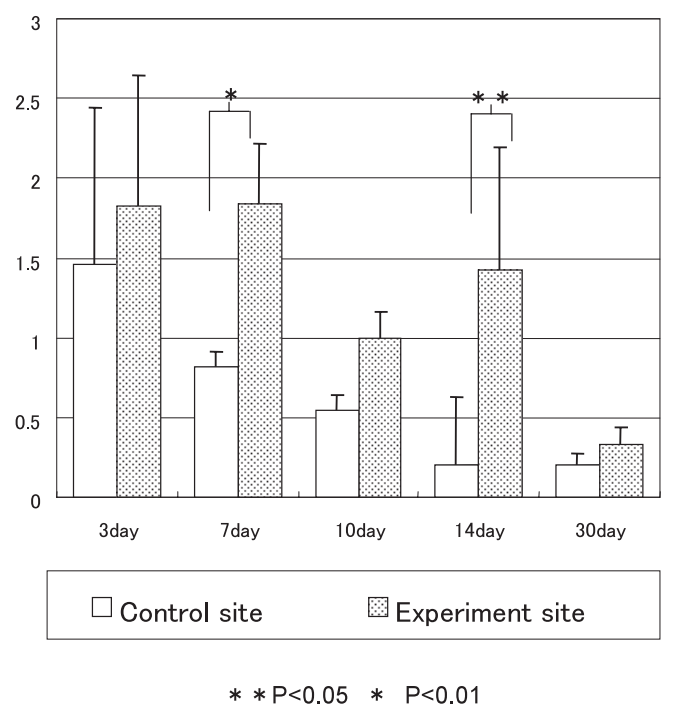

Fig. 11 Osteocalcin mRNA expression was continuously observed throughout the experimental periods in both the control and the experimental groups. Osteocalcin mRNA expression was detected earlier and was greater in the $\beta$-TCP implanted groups than in the control groups and significant differences were observed at 7 and 14 days. 
mation starts within a couple of days, without any preceding osteoclastic resorption. In larger holes, a scaffold of woven bone forms and then lamellar bone is deposited in the newly formed inter-trabecular spaces, which have a corresponding diameter of 150 to $200 \mu \mathrm{m}$. From these facts, $\beta$-TCP used in this study which create a framework porosity of 100 to $200 \mu \mathrm{m}$ has been shown to be optimal for ingrowth of bone cells within bone defects.

In this study, new bone formation in the $\beta$-TCP implanted groups was significantly higher than in the control groups at each of the time periods. Furthermore, new bone formation was equally observed at all of the experimental times in the central and in the side areas of the $\beta$-TCP implantation groups. In contrast, in the control group, the amount of bone formation in the central area was much smaller than in the side area and was finally replaced completely by bone marrow. It seems likely that bone cells can migrate into the central area along the $\beta$-TCP, which is bioactive and creates a proper porosity in the framework.

\section{Bone healing with $\beta$-TCP}

Any type of bone lesion, such as fractures, defects or insertion of implants, activates local bone regeneration by releasing growth factors and inductors. Bone is, in fact, one of the richest sources of growth factors and many growth factors can be detected in bone, including insulin like growth factor (IGF), transforming growth factor (TGF), fibroblast growth factor (FGF), and platelet-derived growth factor (PDGF) (30). In addition, some bone inducing factors are of great interest, such as osteogenin and bone morphogenetic protein (BMP) $(14,15,34-36)$. However, the $\beta$-TCP used in this study is an inorganic compound in which no growth factors or inductors exist, and thus the results of this study suggest that $\beta$-TCP promotes bone formation due to other factors.

Ideally, the material used in osteoconduction should allow a direct deposition of bone on its surface and be replaceable by bone. This is only possible if it can be resorbed and substituted during the remodeling phase of bone repair. By definition, only bioactive materials establish chemical bonds and thus firm attachments to bone (30).

It is known that $\beta$-TCP shows comparable osteogenic ability in the presence of marrow cells. Kasten et al. (18) reported that $\beta$-TCP promotes bone marrow stem cell proliferation and differentiation to osteogenic cells in culture condition (9). Boo et al. (2) reported that $\beta$-TCP loaded with mesenchymal stem cells has excellent osteogenic characteristics, thus supporting its potential in tissue engineering to repair bone defects. Neo et al. (24) used electron microscopy to demonstrate that $\beta$-TCP makes direct contact with the bone, that no apatite layer is present at the interface, that the surface becomes rough due to degradation, and that bone grows into the finest surface irregularities. Kotani et al. (20) also reported that $\beta$-TCP binds to bone through microanchoring between the bone and the rough surface of $\beta$-TCP which is resorbed.

From this study, we suggest that $\beta$-TCP first contributes to the core of calcification in the bone defect and then promotes osteogenesis around the $\beta$-TCP, after which the $\beta$-TCP is resorbed and replaced by bone. However, no phagocytic cells were seen, suggesting that resorption occurs only by a fluid contributed process. This occurs due to acute resorption when the blood flow attaches to the surface of the $\beta$-TCP and is then surrounded by bony granulation tissue. A slow resorption of bone probably occurs by cells which have a phagocytic capability at later time periods.

Bone related protein $m R N A$ expression around $\beta$-TCP

Osteopontin is a protein which regulates calcification in the front line of bone formation $(6,29)$. Osteopontin is produced by osteoblasts and facilitates the adhesion of osteoblasts to the extracellular matrix and accelerates the calcification process. Neo et al. $(22,23)$ reported that collagen is found both on the $\beta$-TCP and between $\beta$-TCP granules, but that osteopontin is found mostly on $\beta$-TCP and is also found in the cytoplasm of macrophages. Ohsawa et al. (28) demonstrated expression of osteopontin mRNA induced by $\beta$-TCP in rat tibia by in situ hybridization, suggesting that osteopontin may play a role in bone formation on the materials and helps to determine their biocompatibility. In agreement with those studies, we now report that osteopontin mRNA expression occurs earlier and is higher in the $\beta$-TCP implanted groups than in control groups at all time periods, although significant differences were observed only at 10 days. It is known that osteopontin is produced not only by osteoblasts, preosteoblast bone cells, and osteoclasts in the remodeling front, but also by macrophages in the inflammation area and by fibroblasts in developmental stages or during wound healing $(8,37)$. In this study, there were no phagocytic cells observed around the $\beta$-TCP throughout the experimental time periods, and this may suggest that osteopontin mRNA expression is 
probably due to bone cells around the $\beta$-TCP.

Osteocalcin is produced only by osteoblasts, has an affinity for bone mineral constituents (11) and implies a role in mineralization of the bone matrices during final osteoblast differentiation. Osteocalcin mRNA expression was continuously observed throughout the experimental periods both in the control and in the experimental groups. This study showed that osteocalcin mRNA expression is upregulated earlier and to higher levels in the $\beta$-TCP implanted groups than in the control groups and significant differences were observed at 7 and at 14 days. These results suggest that bone marrow cells around the $\beta$-TCP influence cell differentiation. It is known that osteogenic cell activity increases with $\mathrm{Ca}$ concentration of local tissue in the bone. This suggests that the $\mathrm{Ca}$ concentration may increase in rat bone marrow osteoblasts during $\beta$-TCP resorption. Nakase et al. (21) reported that osteopontin and osteocalcin are expressed differentially and specifically, in association with extracellular matrix mineralization. Taken together, these results prove that $\beta$-TCP is an appropriate material for osteoconduction and promotes bone formation in bone defects in the absence of bone activators or inducers.

\section{Acknowledgements}

The authors would like to express great gratitude to Mrs. Y. Motoyoshi for her technical assistance and would like to express gratitude to the staff of the Department of Clinical Pathophysiology for their technical assistance and helpful suggestions. This investigation was supported in part by the Ministry of Education, Culture, Sports, Science and Technology, Japan (No.14207093) and Oral Health Science Center Grant (No. TDC-HRC5A08).

\section{REFERENCES}

1. Albrektsson T and Linder L (1981) Intravital, long-term follow-up of autologous experimental bone grafts. Arch Orthop Trauma Surg 98, 189-193.

2. Boo JS, Yamada Y, Okazaki Y, Hibino Y, Okada K, Hata K Yoshikawa T, Sugiura Y and Ueda M (2002) Tissue-engineered bone using mesenchymal stem cells and a biodegradable scaffold. J Craniofac Surg 13, 231-239.

3. Boyne PJ (1964) Regeneration of alveolar bone beneath cellulose acetate filter implants. J Dent Res 43, 827.

4. Boyne PJ (1974) Osseous grafts and implants in the restoration of large oral defects. J Periodontol 45, 378-384.

5. Buser D, Dula K, Belser U, Hirt HP and Berthold H (1993) Localized ridge augmentation using guided bone regeneration. 1. Surgical procedure in the maxilla. Int J Periodont Rest Dent 13, 29-45.

6. Cowles EA, DeRome ME, Pastizzo G, Brailey LL and
Gronowicz GA (1998) Mineralization and the expression of matrix proteins during in vivo bone development. Calcif Tissue Int 62, 74-82.

7. Dahlin C, Gottlow J, Linde A and Nyman S (1990) Healing of maxillary and mandibular bone defects using a membrane technique. Scand J Plast Reconstr Hand Surg 24, 13-19.

8. Dodds RA, Connor JR, James IE, Rykaczewski EL, Appelbaum E, Dul E and Gowen M (1995) Human osteoclast, not osteoblasts, deposit osteopontin onto resorption surfaces: an in vitro and ex vivo study of remodeling bone. J Bone Mineral Res 10, 1666-1680.

9. Dong J, Uemura T, Shirasaki Y and Tateishi T (2002) Promotion of bone formation using highly pure porous $\beta$-TCP combined with bone marrow-derived osteoprogenitor cells. Biomaterials 23: 4493-4502.

10. Eggli PS, Muller J and Willenegger H (1968) Experimentellhistologischer Beitrag zur Entstehung und Behandlung von Pseudarthrosen. H Unfallheil 94, 15-20

11. Fujii K and Inoue H (2002) Biology of Bone and Cartilage. Application of Basic Science for Practice Medicine, pp 2527, Kanehara Co., Tokyo.

12. Goodman S, Aspenberg P, Song Y, Regula D and Lidgren L (1995) Intermittent micromotion and polyethylene particles inhibit bone ingrowth into titanium chambers in rabbits. $J$ Appl Biomater 6, 161-165.

13. Hurley LA, Stinchfield FE, Bassett CAL and Lyon WH (1959) The role of soft tissues in osteogenesis. J Bone Joint Surg 41A, 1243-1254.

14. Inoue T, Deporter DA and Melcher AH (1986) Induction of chondrogenesis in muscle, skin, bone marrow and periodontal ligament by demineralized dentin and bone matrix in vivo and in vitro. $J$ Dent Res $\mathbf{6 5}, 12-22$.

15. Inoue T, Deporter DA and Melcher AH (1986) Induction of cartilage and bone by dentin demineralized in citric acid. $J$ Periodont Res 21, 243-255.

16. Johner R (1972) Zur Knochenheilung in Abhangigkeit von der Defektgrosse. Helv Chir Acta 39, 409-411

17. Jensen OT, Greer RO Jr and Kassebaum D (1995) Vertical guided bone-graft augmentation in a new canine mandibular model. Int J Oral Maxillofac Implants 10, 335-344.

18. Kasten P, Luginbuhl R, Van Griensven M, Barkhausen T, Krettek C, Bohner M and Bosch U (2003) Comparison of human bone marrow stromal cells seeded on calcium-deficient hydroxyapatite, $\beta$-tricalcium phosphate and demineralized bone matrix. Biomaterials 24, 2593-2603.

19. Keller EE, Van Roekel NB, Desjardins RP and Tolman DE (1987) Prosthetic-surgical reconstruction of the severely resorbed maxilla with iliac bone grafting. Int J Oral Maxillofac Implants 2, 155-165.

20. Kotani S, Fujita Y, Kitsugi T, Nakamura T, Yamamuro T, Ohtsuki C and Kokubo T (1991) Bone bonding mechanism of $\beta$-tricalcium phosphate. J Biomed Mater Res 25, 13031315.

21. Nakase T, Takaoka K, Hirakawa K, Hirota S, Takemura T, Onoue H, Takebayashi K, Kitamura Y and Nomura S (1994) Alterations in the expression of ostenectin, osteopontin and osteocalcin mRNAs during the development of skeletal tissues in vivo. Bone Mineral 26, 109-122.

22. Neo M, Herbst H, Voigt CF and Gross UM (1998) Temporal and spatial patterns of osteoblast activation following implantation of $\beta$-TCP particles into bone. J Biomed Mater Res 39, $71-76$.

23. Neo M, Voigt CF, Herbst H and Gross UM (1998) Osteoblast reaction at the interface between surface-active materials and 
bone in vivo: A study using in situ hybridization. $J$ Biomed Mater Res 39, 1-8.

24. Neo M, Kotani S, Fujita Y, Nakamura T and Yamamuro T (1992) Differences in ceramic-bone interface between surface-active ceramics and resorbable ceramics; A study by scanning and transmission electron microscopy. J Biomed Mater Res 26, 255-267.

25. Neo M, Voigt CF, Herbst H and Gross UM (1996) Analysis of osteoblast activity at biomaterial-bone interfaces by in situ hybridization. J Biomed Mater Res 30, 485-492.

26. Nyman S, Lang NP, Buser D and Bragger U (1990) Bone regeneration adjacent to titanium dental implants using guided tissue regeneration. Int J Oral Maxillofac Implants 5, 9-14.

27. Nystrom E, Kahnberg KE and Albrektsson T (1993) Treatment of the severely resorbed maxillae with bone graft and titanium implants; Histologic review of autopsy specimens. Int J Oral Maxillofac Implants 8, 167-172.

28. Ohsawa K, Neo M, Matsuoka H, Akiyama H, Ito H, Kohno $\mathrm{H}$ and Nakamura T (2000) The expression of bone matrix protein mRNA around $\beta$ TCP particles implanted into bone. $J$ Biomed Mater Res 52, 460-466.

29. Sato M, Yasui N, Nakase T, Kawaharta H, Sugimoto M, Hirota S, Kitamura Y, Nomura S and Ochi T (1998) Expression of bone matrix proteins mRNA during distraction osteogenesis. J Bone Mineral Res 13, 1221-1231.

30. Schenk RK (1994) Bone regeneration. Biologic basis. In: Guided Bone Regeneration in Implant Dentistry (Buser D,
Chalin C, Schenk RK, ed.), pp 49-100, Quintessence Publishing, Chicago.

31. Simion M, Dahlin C, Trisi P and Piattelli A (1994) Qualitative and quantitative comparative study on different filling materials used in bone tissue regeneration; A controlled clinical study. Int J Periodont Rest Dent 14, 198-215.

32. Slotte C, Lundgren D and Burgos PM (2003) Placement of autogenous bone chips or bovine bone mineral in guided bone augmentation: a rabbit skull study. Int J Oral Maxillofac Implants 18, 795-806.

33. Tinti C and Parma-Benfenati S (1998) Vertical ridge augmentation; surgical protocol and retrospective evaluation of 48 consecutively inserted implants. Int $J$ Periodontics Restorative Dent 18, 434-443.

34. Urist MR and McLean FC (1952) Osteogenetic potency and new-bone formation by induction in transplants to the anterior chamber of the eye. J Bone Joint Surg 34A, 443-476.

35. Urist MR (1980) Bone transplants and implants. In: Fundamental and Clinical Bone Physiology (Urist MR, ed.), pp 331-368, Lippincott, Philadelphia.

36. Urist MR, Silbermann BF, Buring K, Dubuc FL and Rosenberg JM (1967) The bone inducting principle. Clin Orthop Rel Res 53, 243-283.

37. Yamazaki M, Nakajima F, Ogasawara A, Moriya H, Majeska RJ and Einhorn TA (1999) Spatial and temporal distribution of CD44 and osteopontin in fracture callus. J Bone Joint Surg 81-B, 508-515. 